\title{
Characterization of Poly(Ethylene Terephthalate) by Torque Rheometry
}

\author{
Daniella Stepheny Carvalho Andrade ${ }^{\mathrm{a}}\left(\mathbb{1},{\text { Eduardo Luís Canedo }{ }^{\mathrm{a} \dagger} \text { (), Laura Hecker de Carvalho }}^{\mathrm{b}}\right.$ (1), \\ Renata Barbosac ${ }^{\mathbb{D}}$, Tatianny Soares Alves ${ }^{\mathrm{c} *}$ (1) \\ ${ }^{a}$ Universidade Federal de Pernambuco, Programa de Pós-Graduação em Engenharia Química, Recife, \\ PE, Brasil \\ ${ }^{b}$ Universidade Federal de Campina Grande, Programa de Pós-Graduação em Ciência e Engenharia de \\ Materiais, Campina Grande, PB, Brasil \\ 'Universidade Federal do Piaui, Programa de Pós-Graduação em Ciência e Engenharia dos Materiais, \\ Teresina, PI, Brasil
}

Received: June 01, 2020; Revised: December 23, 2020; Accepted: December 27, 2020

\begin{abstract}
Polymer processing parameters may considerably affect final product characteristic as, if properly chosen, these parameters may lead to products with optimal properties. The aim of this work is to evaluate the rheological characteristics of poly(ethylene terephthalate) (PET) by torque rheometry, as well as to estimate its incipient degradation rate during processing in an internal laboratory mixer. In order to estimate the temperature coefficient of the viscosity $(\beta)$, and the pseudoplasticity index (n) of PET, two sets of experiments need to be performed. In the first one, the polymer is processed at three different temperatures at a single rotor speed for $10 \mathrm{~min}$, getting temperature coefficient of the viscosity equal to $\beta=0.053{ }^{\circ} \mathrm{C}^{-1}$. In the second set of experiments, the resin (PET) is processed at a single temperature at six different rotor speeds for the same time interval and the pseudoplasticity index was determined, $\mathrm{n}=0.78$. From the results obtained, it is possible to indicate the internal mixer as an equipment not only for mixing polymers or composites, but as a tool for determining important rheological variables for predicting degradative processes.
\end{abstract}

Keywords: Poly(ethylene terephthalate), Rheology, Viscosity, Degradation.

\section{Introduction}

The use of poly(ethylene terephthalate) (PET) has steadily grown worldwide in the last decade at a rate of $10 \%$ per year ${ }^{1}$. Nowadays, PET is considered to be one of the most important engineering thermoplastics available ${ }^{2,3}$. The high impact and chemical resistances, excellent thermal, gas and odor barrier properties as well as transparency, easy processing and coloring characteristics are responsible for the wide use of PET in containers for liquids ${ }^{2,4}$. Food packaging generates high volumes of discarded plastics, among which are PET products, which leads to an increase in urban solid waste and to serious environmental problems ${ }^{1,4,5}$. Recycling is the most appropriate method for reducing this kind of damage and PET is one of the most successfully recycled polymers as well as being one of the most recycled resins in Brazil ${ }^{1,5,6}$.

Mechanical recycling, where the waste is ground and washed, followed by extrusion and/or injection molding to generate new products, are the main recycling techniques used for PET residues. The properties of the resulting product, however, are significantly lower than those of virgin PET because weathering of the post-consumed material, grinding and processing (extrusion and/or injection) at high temperatures can induce degradation by a variety of reactions

*e-mail: tsaeng3@yahoo.com.br

$\dagger$ In memorium such as chain scission (which lowers molecular weight) as well as other reactions due to the high reactivity and to the variety of chemical groups present in $\mathrm{PET}^{1,4,7}$.

With the reduction of properties PET is no longer suitable for the manufacture of bottles, being used in films, textile fibers and filler, thermal insulation, and floor covering, electrical and electronic instruments, household utensils, sporting goods, lighting products, automotive products, X-ray sheets, recording tapes, power tools, and these different applications lead to their production with different intrinsic properties ${ }^{1,2}$.

The molecular weight of a polymer relates to its viscosity (see Equation 1) and different processing techniques require different melt viscosities. For example, the spinning process requires low melt viscosity; while for extrusion and injection molding of the same polymer higher, melt viscosities are required ${ }^{1}$. Therefore, the thermal stability of PET during processing is of fundamental importance to obtain good properties in the final product ${ }^{8}$.

The intrinsic viscosity [ $\eta$ ] of commercial PET varies from 0.45 to $1.2 \mathrm{dLg}^{-1}$, with a polydispersity ${ }^{2}$ index generally equal to 2 . The higher viscosity PET resin enables the production of lighter packaging for the pharmaceutical and food industry, including carbonated beverages, carbonated water and cleaning products 9 . 
PET properties are directly dependent on the degree and quality of crystallinity, their crystallization occurs over a wide temperature range, and samples with the same degree of crystallinity at different temperatures have different melting characteristics that often exhibit multiple endotherm fusion ${ }^{10}$. The PET resin has melting point $(\mathrm{Tm})^{2,11}$ between 255 and $265^{\circ} \mathrm{C}$ and density of about 1.38 g.cm ${ }^{-3}$ at $25^{\circ} \mathrm{C}$.

Degradation reactions occur during all stages of PET synthesis and also during processing ${ }^{12}$. PET is degraded by random scission of ester bonds and the rate of thermal degradation is affected by by-products such as acetaldehydes and by stirring conditions of the molten $\mathrm{PET}^{13}$. The high temperatures (between 200 and $300{ }^{\circ} \mathrm{C}$ ) combined with the shear rate required during $\mathrm{PET}$ processing exposes the resin to favorable conditions for degradation reactions resulting in changes in properties such as the decrease in intrinsic viscosity and mass ${ }^{7}$.

Tate and Narusawa ${ }^{13}$ studied the thermal degradation and viscosity of the high molecular weight PET with intrinsic viscosity at $2 \mathrm{dL} \cdot \mathrm{g}^{-1}$ in the melt phase, considering that the PET used had a high melting point due to its high molecular weight. The authors measured the melt viscosity under the shear rate of 0.1 to $10 \mathrm{~s}^{-1}$ after melting the polymer and observed an increase in the rate of degradation with the molecular weight of the resin, concluding that its processing should be conducted with a shorter time and temperature, in order to maintain the molecular weight during the process. The thermal stability of commercial PET has also been studied by Härth et al. ${ }^{8}$ by means of time-dependent zero shear viscosity measurements at a constant frequency. Through the zero shear method it is possible to detect molar mass changes during processing.

Rheological and intrinsic viscosity measurements were performed by Cruz et al. ${ }^{7}$ to determine how the degradation of PET after consumption is affected by the presence of contaminants, reprocessing and solid state polymerization.

Since viscosity is sensitive to minimal changes in molar mass that can be attributed to degradation and torque rheometry is a simple method that can be used for this purpose $\mathrm{e}^{14}$. This work aimed to evaluate the rheological properties of PET by torque rheometry, as well as to estimate the rate of incipient degradation suffered during processing in an internal laboratory mixer.

\section{Experimental}

\subsection{Material}

The resin used was a "bottle grade" poly(ethylene terephthalate) with trade name PQS CDS Plus, manufactured and supplied by Petroquímica Suape (PQS). According to the manufacturer, its intrinsic viscosity, is $0.85 \pm 0.02 \mathrm{dL}^{-1}$. According to the literature ${ }^{9}$ the intrinsic viscosity [ $\left.\eta\right]$ measured in dL.g ${ }^{-1}$ is related to the average molar mass $\bar{M}_{n}$ in g. $\mathrm{mol}^{-1}$ by the Mark-Houwink-Sakurada ratio. Assuming an ideal molar mass distribution, with a polydispersity index IP $=\bar{M}_{w} / \bar{M}_{n}=2$ in Equation 1, we obtain the weight average molar mass $\bar{M}_{w}$.

$[\eta]=3,72 \times 10^{-4} \bar{M}_{n}^{0,73}$

\subsection{Methods}

The PET resin was dried in an air circulation oven at $130{ }^{\circ} \mathrm{C}$ for at least 6 hours prior to processing. The mass of the batch, m, added to the torque rheometry was evaluated by the expression:

$m=\rho f V_{F}$

where $\rho$ is the density of the material at room temperature, $f$ is the fill factor $(70 \%)$ employed and $V_{F}$ is the free volume of the processing chamber. Thus, the batch mass used for the experiments was $300 \mathrm{~g}$.

\subsection{Torque rheometry}

The resin was then processed under different operating conditions as indicated in Table 1 in a Thermo Scientific's Haake Rheomix 3000 laboratory internal mixer operating with roller type rotors. This equipment records the melt temperature $\mathrm{T}\left({ }^{\circ} \mathrm{C}\right)$ and the torque $\mathrm{Z}(\mathrm{N} . \mathrm{m})$ as functions of time $\mathrm{t}(\mathrm{min})$, at the rate of 1 point per second.

Degradation during processing was estimated by torque rheometry according to the procedure and models developed by Canedo and Alves ${ }^{15}$ and Alves et al. ${ }^{16}$, which can be applied for the study of polymer additives, blends and polymer matrix composites $\mathrm{s}^{5,14,17-22}$.

Analysis of $\mathrm{T}(\mathrm{t})$ and $\mathrm{Z}(\mathrm{t})$ during the last stage of processing (the melt processing) allows to estimate the rheological characteristics (viscosity dependence with temperature and shear rate) of the processed material and to evaluate the rate of incipient degradation during processing.

These data allowed for the determination of the incipient degradation during the final processing stages.

Experiments were carried out in two stages: the tests under different chamber wall temperatures $\left(\mathrm{T}_{0}=265,280\right.$ and $\left.295^{\circ} \mathrm{C}\right)$ and fixed rotor speed $(\mathrm{N}=60 \mathrm{rpm})$ were used to estimate the temperature of the viscosity $(\beta)$ while tests with performed at a set wall temperature $\left(\mathrm{T}_{0}=280{ }^{\circ} \mathrm{C}\right)$ and rotor speeds $(\mathrm{N}=30,60,90,120,150$ and $180 \mathrm{rpm})$ to estimate the pseudoplasticity index (n) of the PET resin under the processing conditions.

\subsubsection{Dependence of viscosity with temperature}

In the final stage of processing of polymer systems (neat polymers, blends and polymer matrix composites) in the internal laboratory mixer, torque $(\mathrm{Z})$ is proportional to melt viscosity $(\eta)$ :

$Z=k \eta$

melt viscosity $(\eta)$ exponentially depends on the temperature $\mathrm{T}$ inside the processing chamber (temperature of the molten polymer) and is given by:

$\eta=k_{2} \exp \left\{-\beta\left(T-T^{*}\right)\right\}$

where $T^{*}$ is a (arbitrary) reference temperature and $\beta$ is a temperature coefficient of the viscosity ${ }^{16}$ :

$\beta=-\frac{\partial \ln \eta}{\partial T}$

Therefore:

$Z=k \exp \left\{-\beta\left(T-T^{*}\right)\right\}$ 
Table 1. Operation Conditions.

\begin{tabular}{ccccc}
\hline Identification & $m(\mathrm{~g})$ & $T_{0}\left({ }^{\circ} \mathrm{C}\right)$ & $N(\mathrm{rpm})$ & $t_{m}(\mathrm{~min})$ \\
\hline 1 & 300 & 265 & 60 & 10 \\
\hline 2 & 300 & 280 & 60 & 10 \\
\hline 3 & 300 & 295 & 60 & 10 \\
\hline 4 & 300 & 280 & 90 & 10 \\
\hline 5 & 300 & 280 & 120 & 10 \\
\hline 6 & 300 & 280 & 150 & 10 \\
\hline 7 & 300 & 280 & 180 & 10 \\
\hline 8 & 300 & 280 & & 10 \\
\hline
\end{tabular}

or

$\ln Z=\ln k-\beta\left(T-T^{*}\right)$

where $\mathrm{k}=\mathrm{k}_{1} \cdot \mathrm{k}_{2}$ is a constant for tests performed under the same and in the same apparatus and operational conditions (mixer/rotor combination, fill factor and rotor speed). Under these conditions, the temperature coefficient of the viscosity $\beta$ can be obtained by linear regression of $\ln Z$ versus (T-T*), with the mean values of $Z=Z(t)$ and $T=T(t)$ in a smalltime interval.

\subsubsection{Dependence of viscosity which strain rate}

During processing of molten polymers in the internal mixer, there is predominantly shear flow. The deformation rate can be associated with shear rate, which depends on rotor speed $(\mathrm{N})$ and the geometry of the equipment. It can be proved that, for a fluid whose rheological characteristics can be represented by the power law, torque is given by ${ }^{15}$ :

$Z=k_{3} N^{n} \exp \left\{-\beta\left(T-T^{*}\right)\right\}$

where $n$ is the pseudoplasticity index (or power law index) given by:

$$
n=1+\frac{\partial \ln \eta}{\partial \ln \gamma}
$$

and $\mathrm{k}_{3}$ is a constant for tests performed with the same polymer on a given apparatus operating at the same fill factor and with the same mixer/rotor combination.

During processing, melt temperature increases above the wall temperature of the chamber due to friction and heat dissipation. Rising temperatures decrease viscosity and hence, torque. Therefore, one cannot directly compare the final torque necessary to process a given polymer and conclude if degradation during processing occurred. In order to do so, it is imperative to remove the temperature effect on viscosity. This can be achieved by calculating the adjusted torque $Z^{*}$, i.e., the torque which would be observed if all samples achieved the same temperature (reference temperature $\mathrm{T}^{*}$ ) during processing:

$$
Z^{*}=Z \exp \left\{+\beta\left(T-T^{*}\right)\right\}
$$

With respect to the adjusted torque $Z^{*}$, Equation 8 is:

$$
Z^{*}=k_{3} N^{n}
$$

$$
\ln Z^{*}=\ln k_{3}+n \ln N
$$

Under these conditions, the viscosity index (n) can be obtained by linear regression of $\ln \mathrm{N}$ versus the mean value of $\ln Z^{*}$ in a minor interval at the final stages of processing.

\subsubsection{Degradation and recovery during processing}

The above expressions assume stable polymeric resins, i.e., whose molar masses do not vary during processing. However, most polymers gradually degrade during processing under moderately high temperatures and shear, which leads to a decrease in their mean molar mass. For a fluid whose rheological characteristics is represented by the power law, the "constant" $\mathrm{k}$ of Equation 6 is a function of the weight average molar mass ${ }^{15} \bar{M}_{w}$ :

$k \approx k^{\prime} \bar{M}_{w}^{2,5+n}$

Taking into account the definition of adjusted torque Equation 10, then:

$Z^{*} \approx k^{\prime} \bar{M}_{w}^{2,5+n}$

Consequently, the relative rate of change of the adjusted terminal torque, i.e., the torque obtained in the final stages of processing, is:

$R_{Z}=\frac{1}{Z^{*}} \frac{d Z^{*}}{d t}$

$R_{Z}$ is a measure of the rate of degradation $\left(R_{Z}<1\right)$ or chain extension $\left(R_{z}>1\right)$ and $100 R_{Z}$ is the $\%$ torque variation adjusted per unit time at the final stage of processing.

$R_{z}$ was evaluated for all tests using the already estimated temperature coefficient of the viscosity $\beta$ to calculate the adjusted torque $Z^{*}(t)$ in a minor interval and by linear regression of $Z^{*}$ versus the time $t$, the derivative $d Z^{*} / \mathrm{dt}$ is obtained.

If the pseudoplasticity index (n) is known, then it is possible to estimate the rate of variation of the weight average molar mass during the last stages of processing as:

$R_{M}=\frac{1}{\bar{M}_{w}} \frac{d \bar{M}_{w}}{d t}=\frac{1}{2,5+n} R_{Z}$

\section{Results and Discussion}

Torque is the rate of mechanical energy consumption (power) within the processing chamber ${ }^{23}$. Figure 1 and 2 shows the temperature of the material inside the mixing 


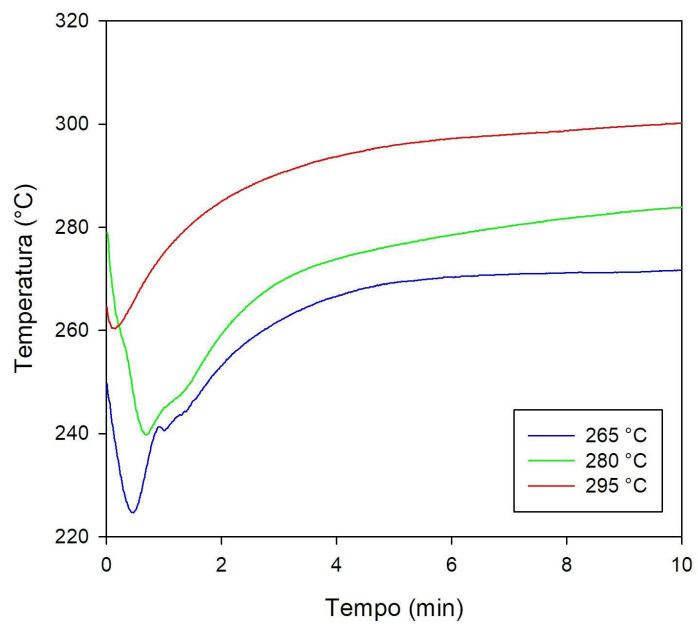

(a)

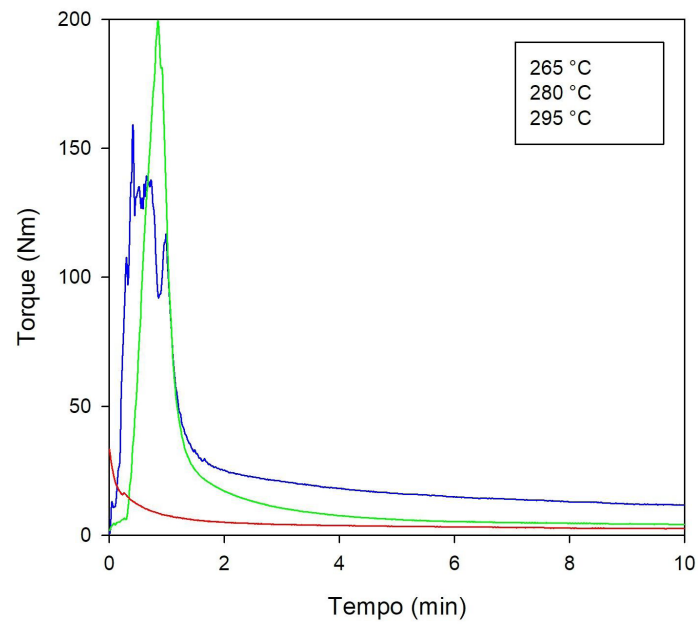

(b)

Figure 1. Temperature (a) and torque (b) as a function of time for tests performed at a given rotor speed $(N=60 \mathrm{rpm})$ at various chamber wall temperatures.

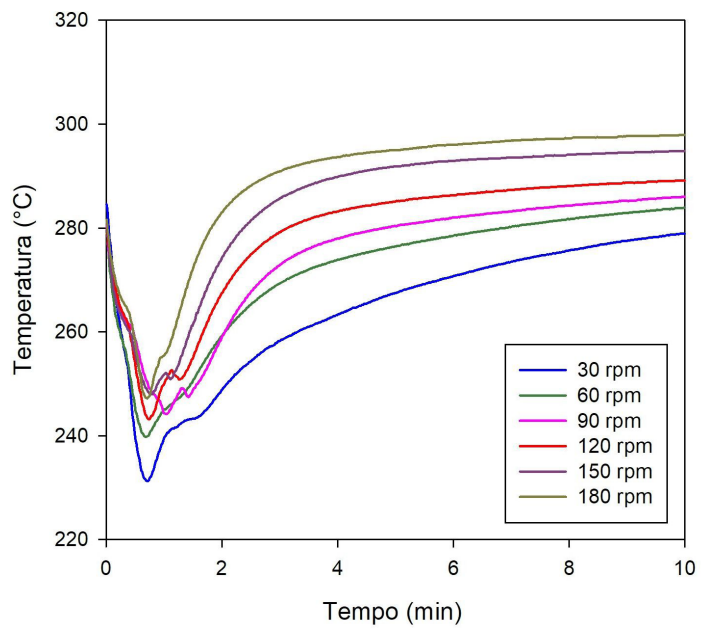

(a)

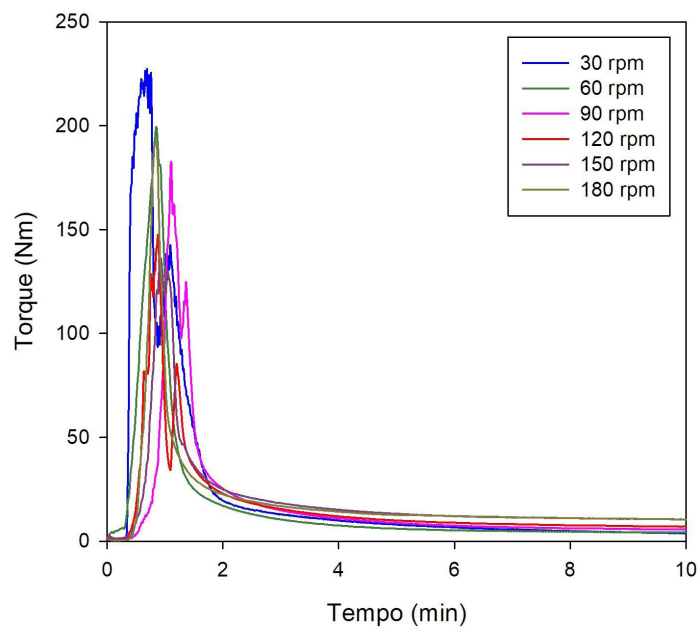

(b)

Figure 2. Temperature (a) and torque (b) as a function of time for testes performed at a given chamber temperature $\left(T_{0}=280{ }^{\circ} \mathrm{C}\right)$ under various rotor speeds.

chamber $(\mathrm{T})$ and the torque required to rotate the rotors $(\mathrm{Z})$ as functions of the processing time. The equipment wall chamber is set at a given temperature and the rotors set at a predefined speed.

Calibration of the equipment is performed at the set temperature while the rotors are rotating in an empty chamber. Torque set to zero under these conditions, similar to a balance tare. The chamber is opened, the desired amount of material is rapidly fed into the equipment, the chamber is closed and torque and temperature as functions of time are measured at $1 \mathrm{~s}$ intervals. A torque peak is observed due to load addition, friction dissipation and plastic deformation. Heat dissipation mechanical energy increase the temperature inside the chamber by melting the polymer matrix, resulting in the decrease of the torque ${ }^{16,20}$.
Torque and temperature then tend to stabilize as the polymer completely melts. For the material investigated here, the initiation of torque and temperature stabilization was observed from $5 \mathrm{~min}$ of polymer processing indicating that the polymer is substantially molten in the second half of the processing (5-10 min time interval), even though the steady state was not reached during the $10 \mathrm{~min}$ of processing.

The final 8-10 min processing interval was chosen for the rheological characterization of PET, due to the small torque variation and complete polymer melting, tending to the steady state, using a reference temperature $\mathrm{T}^{*}=280^{\circ} \mathrm{C}$. According to Equation 4, the viscosity, besides being dependent on the friction by means of the shear rate, is also temperature dependent, being a decreasing function thereof, such dependence implies that the viscosity variation with the temperature will be higher the higher the viscosity and 
vice versa. The mean temperature and torque at a constant rotation $(\mathrm{N}=60 \mathrm{rpm})$ were evaluated and the temperature coefficient of the viscosity $(\beta)$ was estimated by linear regression as indicated in Methodology, Equation 7 and shown in Figure 3, yielding the value: $\beta=0.053{ }^{\circ} \mathrm{C}^{-1}$.

The change in torque, which solely depends on changes in viscosity due to polymer structure modifications such as lowering or increase in the molar mass, can be obtained by eliminating the effect of temperature on viscosity (and hence on torque). Once this is done it is possible to evaluate if polymer degradation due to chain scission, which decreases molar mass or crosslinking, which increases molar mass, takes place.

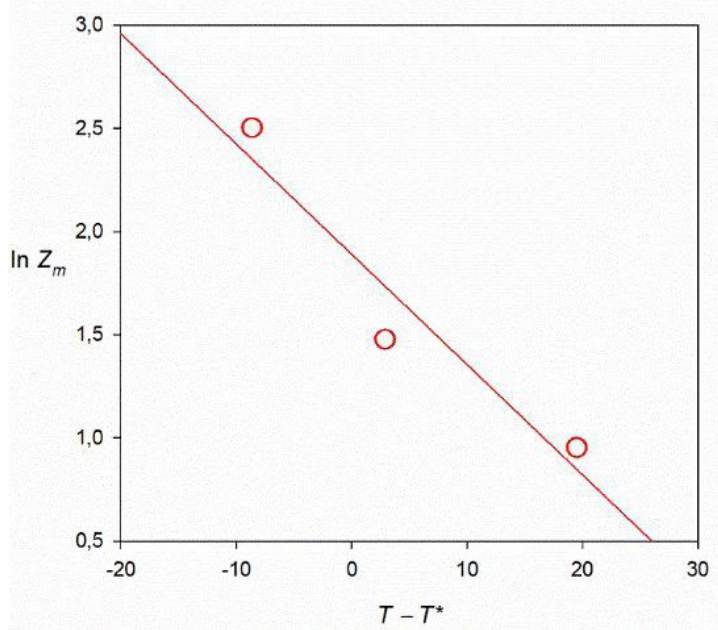

Figure 3. Logarithm of the average torque as a function of different chamber wall temperatures $\left(265,280\right.$ and $\left.295{ }^{\circ} \mathrm{C}\right)$; reference temperature $\mathrm{T}^{*}=280^{\circ} \mathrm{C}$ at the $8-10 \mathrm{~min}$ interval for tests performed at a set rotor speed $(60 \mathrm{rpm})$.
Torque was adjusted to a reference temperature $\left(280^{\circ} \mathrm{C}\right)$ and obtained according to Equation 10, using the previously estimated $\beta$ coefficient value. Results are shown in Figure 4 for the last two minutes of processing (8-10 min interval).

The data show that there was a slight decrease of the adjusted torque, mainly with $\mathrm{N}=180 \mathrm{rpm}$, yet it is observed that the adjusted torque is virtually constant within the time and temperature range of the experiment, indicating that the polymer was stable during processing The data also show torque values to be significantly higher at rotor speeds greater than $120 \mathrm{rpm}$.

Figure 5 shows the mean temperature and mean adjusted torque in the last 2 minutes of processing obtained at different rotor speeds.

The pseudoplasticity index $(n)$ was estimated by linear regression of $\ln Z^{*}$ versus $\ln N$ as shown in Figure 6 , for the tests performed under rotational speeds between $30 \mathrm{rpm}$ and $120 \mathrm{rpm}$, according to Equation 12. A value of $n=0.78$ was obtained for PET, indicating that the fluid power law is pseudoplastic $(\mathrm{n}<1)^{16}$.

The average temperature in the melt, the adjusted torque, the rate of change of the adjusted torque at the end of processing (8-10 min time interval), the relative rate of torque variation $\left(\mathrm{R}_{\mathrm{z}}\right)$ and the relative rate of molar mass variation $\left(\mathrm{R}_{\mathrm{M}}\right)$ estimated with Equation 15 and 16 are displayed in Table 2 .

The data shows that melt temperature increased with rotor speed and that, in general, PET slightly degraded during processing, especially when processed at higher rotor speeds (>90 rpm). This is to be expected and can be associated with increasing mechanical shear and temperatures, which the polymer was subjected during processing. Surprisingly, an increase in the molar mass, $\mathrm{Rz}>0$, when processed at $60 \mathrm{rpm}$ was observed.

Figure 7 shows the rate of change of the weight average molar mass during the final stages of processing.

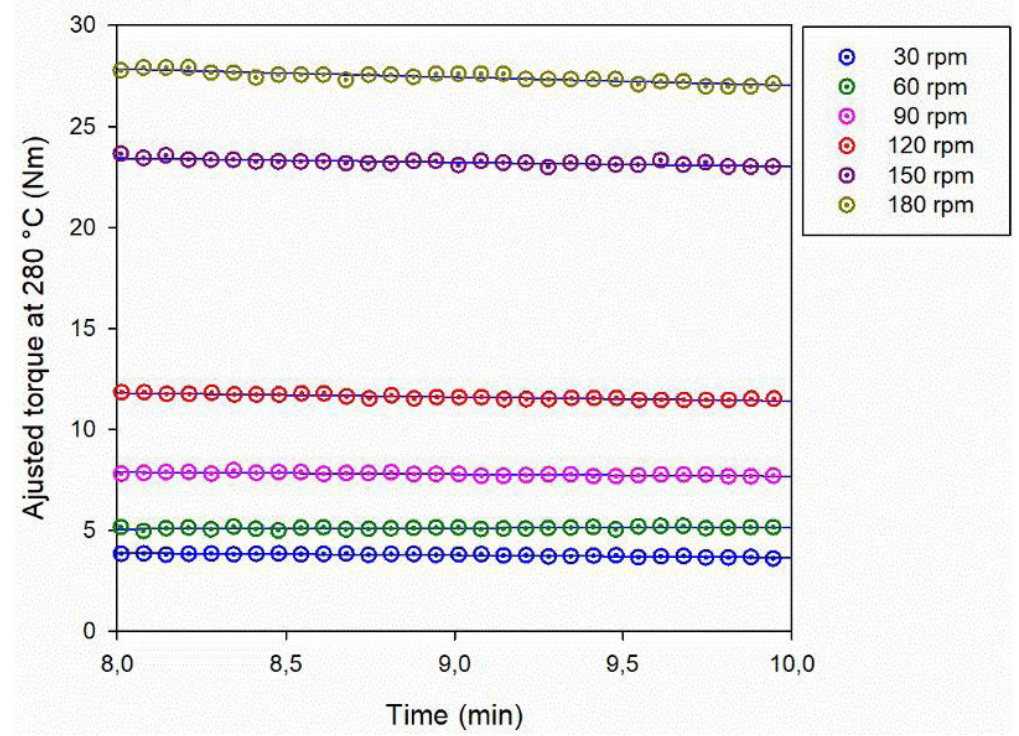

Figure 4. Adjusted Torque as a function of time in the 8-10 min processing time interval, for experiments performed at constant wall temperature and varying rotor speeds. 


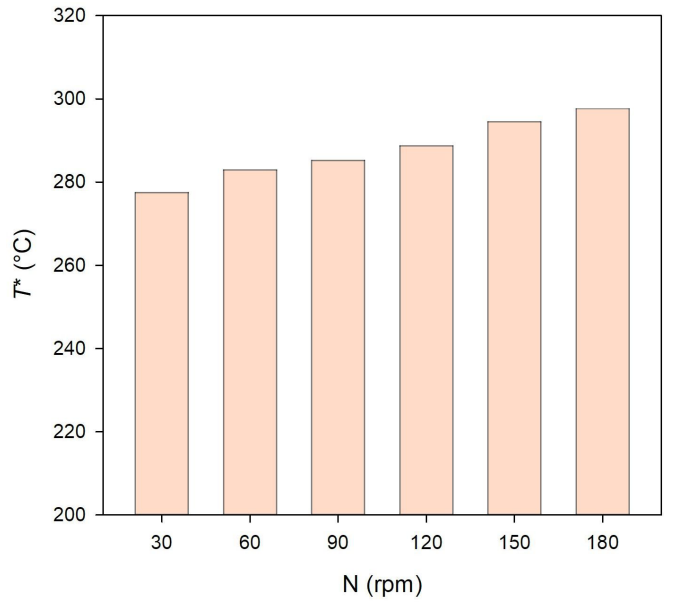

(a)

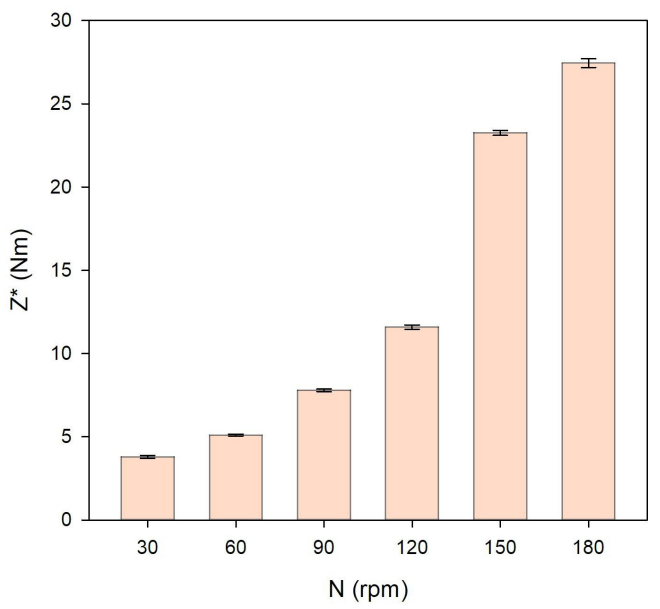

(b)

Figure 5. Average Temperature (a) and average adjusted torque (b) obtained at different rotor speeds for experiments carried out at $280{ }^{\circ} \mathrm{C}$.

Table 2. Estimated parameters for degradation rates or chain extension of PET processed in an internal mixer.

\begin{tabular}{ccccc}
\hline$N(\mathrm{rpm})$ & $\bar{T}\left({ }^{\circ} \mathrm{C}\right)$ & $\overline{Z^{*}}(\mathrm{Nm})$ & $R_{Z}(\% / \mathrm{min})$ & $R_{M}(\% / \mathrm{min})$ \\
\hline 30 & $277.5 \pm 1.0$ & $3.79 \pm 0.09$ & $-3.1 \pm 0.3$ & $-0.95 \pm 0.09$ \\
\hline 60 & $282.9 \pm 0.6$ & $5.10 \pm 0.06$ & $+1.1 \pm 0.2$ & $+0.35 \pm 0.05$ \\
\hline 90 & $285.2 \pm 0.5$ & $7.79 \pm 0.08$ & $-1.3 \pm 0.1$ & $-0.41 \pm 0.04$ \\
\hline 120 & $288.7 \pm 0.3$ & $11.59 \pm 0.13$ & $-1.8 \pm 0.1$ & $-0.54 \pm 0.03$ \\
\hline 150 & $294.5 \pm 0.2$ & $23.26 \pm 0.15$ & $-0.7 \pm 0.1$ & $-0.22 \pm 0.02$ \\
\hline 180 & $297.6 \pm 0.2$ & $27.45 \pm 0.26$ & $-1.5 \pm 0.1$ & $-0.45 \pm 0.02$ \\
\hline
\end{tabular}

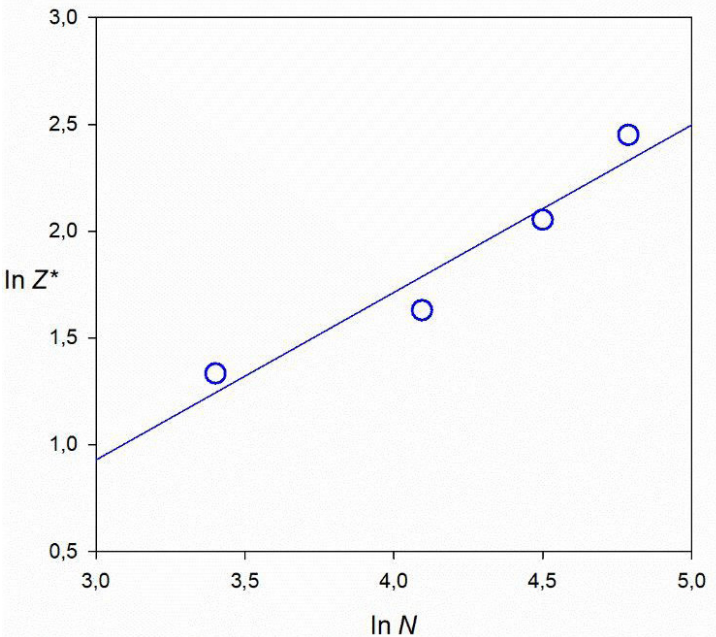

Figure 6. Logarithm of the adjusted torque versus the logarithm of the rotor speed for tests performed at constant chamber wall temperature.

The data indicates that the relative rate of variation of the weight average molar mass is negative (except at $60 \mathrm{rpm}$ ), which suggests incipient degradation during the last stage of processing. However, the small observed values, $\left|\mathrm{R}_{\mathrm{M}}\right|<1 \%$ per minute of processing, do not allow to state that degradation did occur, because although the torque rheometry points to incipient degradation, the small variation in the molar mass is well within the precision of data acquisition.

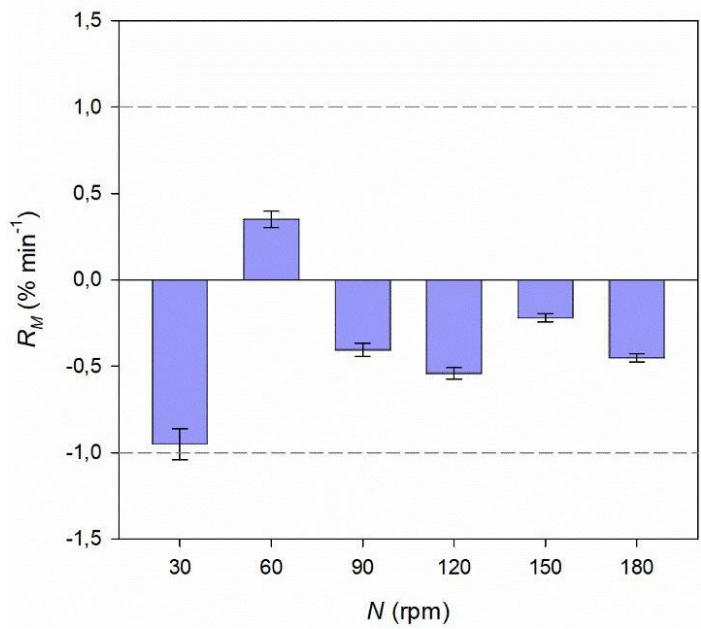

Figure 7. Relative rate of change of the weight average molar mass for different speeds of rotation. The dashed lines delimit the zone.

\section{Conclusions}

The torque rheometry performed in an internal laboratory mixer allowed the investigation of the rheometric behavior of the PET resin during processing under different conditions of rotor speed and temperature. The rheological analysis made it possible to estimate the viscosity temperature coefficient, $\beta=0.053{ }^{\circ} \mathrm{C}^{-1}$, and the pseudoplasticity index, $\mathrm{n}=0.78$, indicating that PET behaves like a non-Newtonian fluid. 
In addition, changes in torque and molar mass in the last stages of processing were also estimated, which indicated minimal degradation of the resin even in the most intense process conditions. The modeling of rheological parameters in an internal mixer proved to be valuable, expanding the possibilities of applying this equipment, not only as a mixing element, but as a resource for predicting degradation phenomena in polymeric resins.

\section{Acknowledgements}

The authors acknowledge the University Federal of Piauí (UFPI) and University Federal of Campina Grande (UFCG) for making the research available.

\section{References}

1. Fakirov S. Condensation polymers: their chemical peculiarities offer great opportunities. Prog Polym Sci. 2019;89:1-18. http:// dx.doi.org/10.1016/j.progpolymsci.2018.09.003 .

2. Awaja F, Pavel D. Recycling of PET. Eur Polym J. 2005;41:145377. http://dx.doi.org/10.1016/j.eurpolymj.2005.02.005.

3. Romão W, Franco MF, Corilo YE, Eberlin MN, Spinacé MAS, De Paoli MA. Poly (ethylene terephthalate) thermo-mechanical and thermo-oxidative degradation mechanisms. Polym Degrad Stabil. 2009;94:1849-59. http://dx.doi.org/10.1016/j. polymdegradstab.2009.05.017.

4. Badia JD, Martinez-Felipe A, Santonja-Blasco L, Ribes-Greus A. Thermal and thermo-oxidative stability of reprocessed poly(ethylene terephthalate). J Anal Appl Pyrolysis. 2013;99:191202. http://dx.doi.org/10.1016/j.jaap.2012.09.003.

5. Tavares AA, Silva DFA, Lima PS, Andrade DLACS, Silva SML, Canedo EL. Chain extension of virgin and recycled polyethylene terephthalate. Polym Test. 2016;50:26-32. http:// dx.doi.org/10.1016/j.polymertesting.2015.11.020.

6. ABIPET: Associação Brasileira da Indústria [Internet]. Censo da reciclagem de PET no Brasil. 10. ed. São Paulo: ABIPET; 2016 [cited 2018 Aug 1]. Available from: http://www.abipet. org.br/index.html? method=mostrarDownloads\&categoria.id=3

7. Cruz SA, Scuracchio CH, Fitaroni LB, Oliveira C. The use of melt rheology and solution viscometry for degradation study of post-consumer poly(ethylene terephthalate): the effects of the contaminants, reprocessing and solid state polymerization. Polym Test. 2017;60:236-41. http://dx.doi.org/10.1016/j. polymertesting.2017.03.026.

8. Härth M, Kaschta J, Schubert DW. Rheological study of the reaction kinetics in a poly(ethylene terephthalate) melt. Polym Degrad Stabil. 2015;120:70-5. http://dx.doi.org/10.1016/j. polymdegradstab.2015.06.001.

9. Fakirov S. Polyethylene terephthalate. In: Olabisi O, editor. Handbook of thermoplastics. New York: Marcel Dekker; 1997. p. 449-64.
10. Kong Y, Hay JN. Multiple melting behaviour of poly(ethylene terephthalate). Polymer (Guildf). 2002;44:623-33. http://dx.doi. org/10.1016/S0032-3861(02)00814-5.

11. Zoller P, Walsh DJ. Standard pressure-volume-temperature data for polymers. Lancaster: Technomic Publishing; 1995.

12. Ravindranath K, Mashelkar RA. Polyethylene terephthalate-I. Chemistry, thermodynamics and transport properties. Chem Eng Sci. 1986;41:2197-14. http://dx.doi.org/10.1016/00092509(86)85070-9.

13. Tate $S$, Narusawa $H$. Thermal degradation and melt viscosity of ultra-high-molecular-weight poly(ethylene terephthalate). Polymer (Guildf). 1996;37:1583-7. http://dx.doi.org/10.1016/00323861(96)83706-2.

14. Almeida TG, João JE, Costa ARM, da Silva AS, Carvalho LH, Canedo EL. Degradation during processing in poly(butylene adipate-co-terephthalate)/vegetable fiber compounds estimated by torque rheometry. Polym Test. 2016;55:204-11. http://dx.doi. org/10.1016/j.polymertesting.2016.08.018.

15. Canedo EL, Alves TS. Processamento de polímeros no misturador interno de laboratório. In: Workshop. CFD/UFCG; 2015; Campina Grande. Anais. Campina Grande: UFCG; 2015.

16. Alves TS, Silva JE No, Silva SML, Carvalho LH, Canedo EL. Process simulation of laboratory internal mixers. Polym Test. 2016;50:94-100. http://dx.doi.org/10.1016/j. polymertesting.2016.01.002.

17. Costa ARM, Almeida TG, Silva SML, Carvalho LH, Canedo EL. Chain extension in poly(butylene-adipate-terephthalate). Inline testing in a laboratory internal mixer. Polym Test. 2015;42:11521. http://dx.doi.org/10.1016/j.polymertesting.2015.01.007.

18. Duarte IS, Tavares AA, Lima PS, Andrade DLACS, Carvalho LH, Canedo EL, et al. Chain extension of virgin and recycled poly(ethylene terephthalate): effect of processing conditions and reprocessing. Polym Degrad Stabil. 2016;124:26-34. http:// dx.doi.org/10.1016/j.polymdegradstab.2015.11.021.

19. Marinho VAD, Pereira CAB, Vitorino MBC, Silva AS, Carvalho LH, Canedo EL. Degradation and recovery in poly(butylene adipate-co-terephthalate)/ thermoplastic starch blends. Polym Test. 2017;58:166-72. http://dx.doi.org/10.1016/j. polymertesting.2016.12.028.

20. Lima PS, Brito RSF, Santos BFF, Tavares AA, Agrawal P, Andrade DLACS, et al. Rheological properties of HDPE/ chitosan composites modified with PE-g-MA. J Mater Res. 2017;32:775-87. http://dx.doi.org/10.1557/jmr.2016.519.

21. Reul LTA, Pereira CAB, Sousa FM, Santos RM, Carvalho LH, Canedo EL. Polycaprolactone/babassu compounds: Rheological, thermal, and morphological characteristics. Polym Compos. 2019;40(51):E540-9. http://dx.doi.org/10.1002/pc.24861.

22. Sousa FM, Costa ARM, Reul LTA, Cavalcanti FB, Carvalho LH, Almeida TG, et al. Rheological and thermal characterization of PCL/PBAT blends. Polym Bull. 2019;76:1573-93. http:// dx.doi.org/10.1007/s00289-018-2428-5.

23. Canedo EL. Processamento de polímeros no misturador interno de laboratório. 2. ed. Campina Grande: Universidade Federal de Campina Grande; 2017. 